\title{
Long-term effects of non-surgical therapy for obesity on cardiovascular risk management: a weighted empirical review
}

\author{
Kurt Laederach-Hofmann • Nadine Messerli-Burgy • \\ Katharina Meyer
}

Received: 6 July 2007 / Accepted: 9 October 2007 / Published online: 8 November 2007

(C) Springer-Verlag 2007

\begin{abstract}
Weight loss affects cardiovascular risk profiles in obese patients. Surgery is not a plausible or viable response to the public health problem of obesity, given that more than $30 \%$ of adults are obese in some countries. However, most studies investigating the effects of weight loss on the cardiovascular risk profile are focussed on weight loss and limited to short-term effects. Since newer data show a rebound of cardiovascular risks in studies that complete a short-term follow-up, the question arises whether, and to what extent, long-term treatments offer a more sustained cardiovascular benefit beside the extensive or less marked weight loss. Aims The purpose of this article is to critically review existing data on the long-term cardiovascular effects of weight loss in obese and overweight patients treated with dietary interven-
\end{abstract}

K. Laederach-Hofmann

Center for Obesity, Nutritional Psychology, and Prevention of Eating Disorders, Division of Endocrinology, Diabetology, and Clinical Nutrition, Inselspital, University of Berne,

Berne, Switzerland

\section{N. Messerli-Burgy}

Psychobiology Group, Department of Epidemiology

and Public Health, University College London,

London, UK

N. Messerli-Burgy

Institute of Psychology, Clinical Psychology

and Psychotherapy Unit, University of Berne,

Berne, Switzerland

K. Meyer

Swiss Health Observatory and University of Berne,

Berne, Switzerland

K. Laederach-Hofmann $(\bowtie)$

ZAEP, University of Berne, Inselspital,

CH-3010 Berne, Switzerland

e-mail: laederach@insel.ch tions, physical activity programmes, behavioural therapy and pharmacological treatments and their combination. Method Inclusion criteria were peer-reviewed, randomized controlled trials (RCT) in the English language which presented data on cardiovascular effects at a follow-up of at least 18 months during or after weight reduction interventions. The search was limited to adults and the publication years between 1990 and 2007. Studies of patients with diagnoses such as coronary heart disease and cancer, and medically treated diabetes and hypertension were excluded. Results Twentythree studies measured cardiovascular risk factors after 18 months or more. Mean BMI was $33.9 \mathrm{~kg} / \mathrm{m} 2$ including 13,733 patients. Mean duration of the studies was 37 months with a dropout rate of $16.1 \%$ on average. Regardless of the absolute amount of weight loss a positive effect on cardiovascular risk factors such as blood pressure, lipids and glucose tolerance was found.

Keywords Cardiovascular risk profile · Weight loss . Non-surgical therapy $\cdot$ RCTs

$\begin{array}{ll}\text { Abbreviations } & \\ \text { BMI } & \text { body mass index } \\ \text { RCTs } & \text { randomized controlled trials } \\ \text { LDL cholesterol } & \text { low-density lipoprotein cholesterol } \\ \text { HDL cholesterol } & \text { high-density lipoprotein cholesterol }\end{array}$

\section{Introduction}

Obesity is a problem with an increasing prevalence in the last several decades. Evidence links obesity to an increased morbidity and mortality risk and a general limitation in quality of life in adults (Orzano and Scott 2004). Life 
expectancy is reduced in obese men by 3.3 years and by 6.9 years in obese women compared with normal weight subjects (Pardo Silva et al. 2006). An increased incidence of diabetes mellitus, an increased mortality rate (Yan et al. 2006), and an increase in cardiovascular risk factors (Kannel et al. 2002) are well known. However, obesity may compromise health status at all levels of risk and greatly influences physical functioning through inflammatory, endocrine and cardiovascular pathways (Lee and Aronne 2007). Moreover, epidemiologic studies have established that cardiovascular risk factors are even identifiable in obese children, predicting a higher cardiovascular risk at adulthood (Berenson and Srinivasan 2001).

A variety of treatment options is available for helping people lose weight, including dietary interventions, physical activity programmes, behavioural therapy and pharmacological treatments and their combination. Surgical interventions are usually a last attempt to support weight change and are often indicated in only a limited number of patients. Since no one would seriously consider surgery as a response to the public health problem of obesity, given that more than $30 \%$ of adults are obese in some countries, we have to emphasise the long-term cardiovascular effects of weight loss by other means. For several reasons, surgery especially has been regarded as the most important tool to reduce cardiovascular risk in obese or morbidly obese patients. However, most studies have only investigated short-term effects or have not been designed in a randomised controlled manner. Since newer data are showing a rebound of cardiovascular risks in successfully surgically treated obese patients after 4 to 6 years, the question arises whether and to what extent long-term treatments including surgical or non-surgical options offer a more sustained cardiovascular benefit beside the extensive or less marked weight loss.

In addition to effects on quality of life and general wellbeing, an important objective of obesity interventions is to reduce cardiovascular risk factors. Non-surgical therapies have been shown to be effective in changing weight, but studies have often been restricted to short-term results. Excess body weight over many years may include irreversible metabolic effects, since data support a vicious circle of endocrine, autonomic and central nervous effects of excess body weight described as the "metabolic domino effect" (Itoh 2003). An overview of the effects of obesity interventions on long-term cardiovascular risk is therefore warranted.

\section{Methods}

We conducted a systematic search and reviewed the relevant literature on weight loss and its cardiovascular effects using Medline, Pubmed, EMBASE, Science Citation Index, PsychInfo and Cochrane Library databases.
Inclusion criteria were (1) peer-reviewed articles in English language which presented data on cardiovascular effects at a (2) follow-up of at least 18 months during or after weight reduction interventions. Search strategies used the key words obesity, weight loss, weight reduction, and cardiovascular risk. The search was limited to (3) adults, investigated by means of (4) randomised controlled trials (RCTs), and (5) published between 1990 and 2007. Articles on patients with additional diagnoses such as coronary heart disease, cancer, medically treated diabetes and medically treated hypertension were excluded. In addition to the database searches, we reviewed references from existing reviews and meta-analyses. Published papers were then thoroughly analysed to gather their effects comparing control to treatment groups.

\section{Results}

\section{Summary of studies}

Twenty-three RCTs fulfilled the search and inclusion criteria of long-term changes in cardiovascular risk factors of 18 months or more. Studies of dieting, exercising, behavioural and pharmacological treatment as well as their combinations were included. Mean follow-up was $34.3 \pm 14.6$ months. The parameters investigated were blood pressure, glucose and insulin, and lipids such as total cholesterol, low-density lipoprotein (LDL) cholesterol and high-density lipoprotein (HDL) cholesterol and triglycerides. Participants were either overweight or obese (mean BMI 33.2 \pm 3.77 ). The studies included in this review are summarised in Table 1 according to their intervention style.

\section{Dietary counselling}

Dietary modification is one of the major methods of controlling obesity, but there are a great variety of dietary intervention methods. Studies examining cardiovascular long-term effects have shown positive effects on several cardiovascular risk factors when weight was reduced even in small amounts.

The Hypertension Prevention Trial Research Group (1990) was conducted with a total sample of 841 healthy subjects with a diastolic blood pressure of 78 to $89 \mathrm{mmHg}$. They were randomized to one of four dietary counselling treatment groups (reduced calories, reduced sodium, reduced sodium and calories, or reduced sodium and increased potassium) or a control group. At 3 years, the low calorie group showed the largest net reduction in mean blood pressure. Similarly, positive findings on fasting plasma glucose were shown in a low-fat diet study on participants with glucose intolerance at 5-year follow-up 


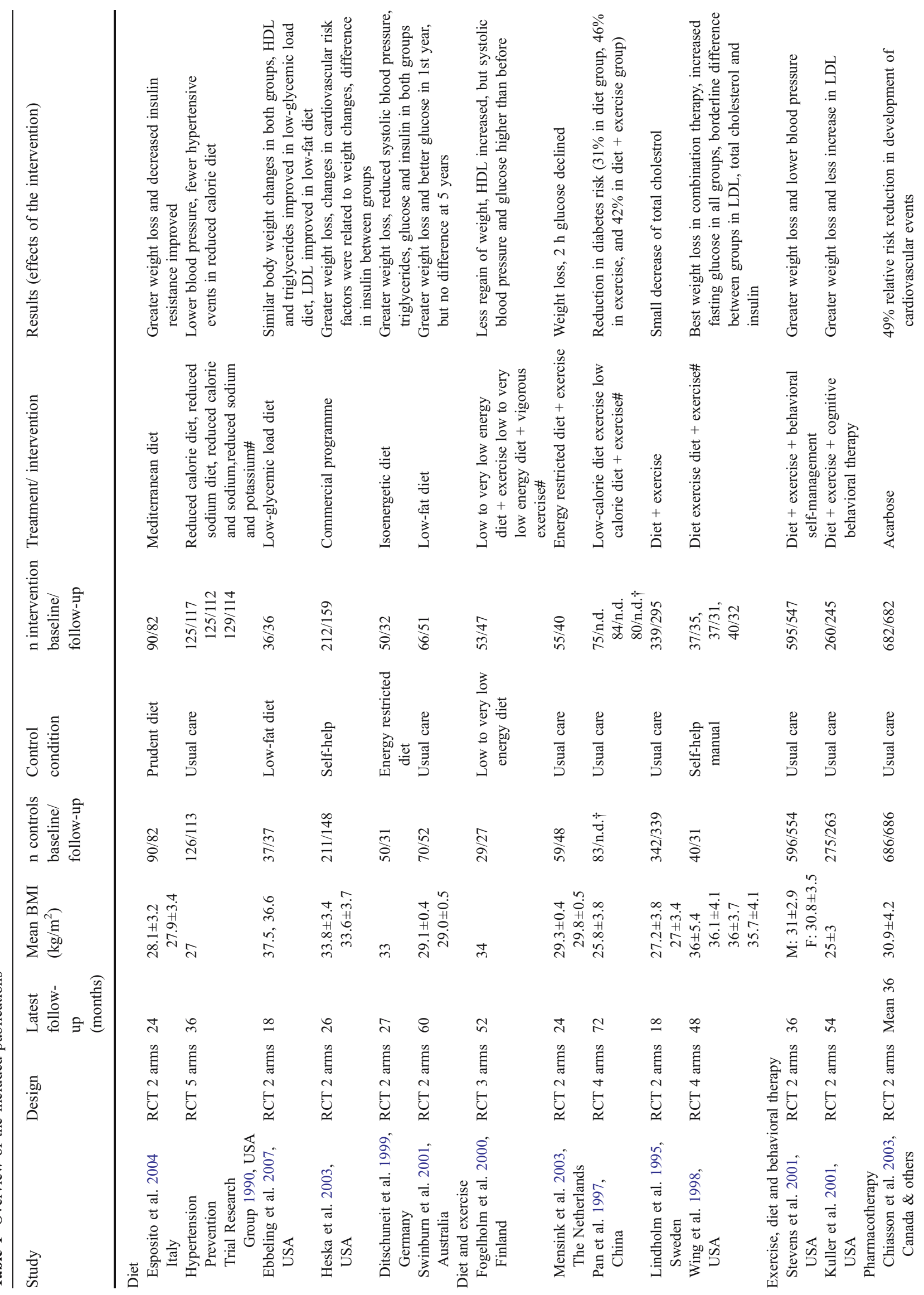




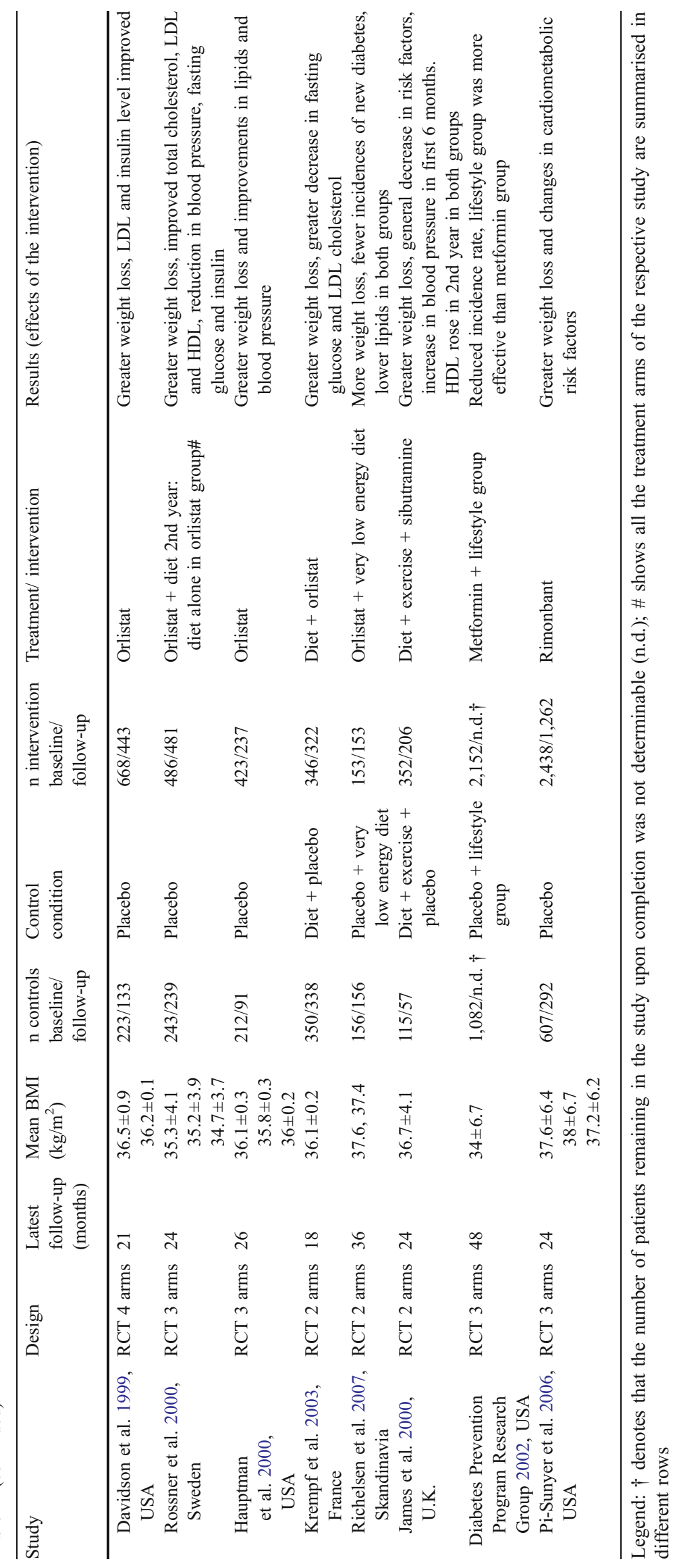


(Swinburn et al. 2001). A recent comparison of a low-fat diet and a low-glycaemic load diet showed an improvement in HDL cholesterol and triglycerides in the low-glycaemic load diet, whereas LDL cholesterol changed in the low-fat diet (Ebbeling et al. 2007).

Two studies investigated obese and overweight subjects using proprietary or commercial diet treatments. Heska et al. (2003) found a better weight loss in a commercial weight reduction programme (Weight Watchers) than in a self-help programme and demonstrated significant differences between the intervention and the control group in plasma insulin level after the 2nd year. Both groups showed improvements in lipids, but fasting glucose increased in both groups. These cardiovascular changes were related to the amount of weight loss. Similar findings have been described by Ditschuneit et al. (1999) in a comparison of energy-restricted diet and an isoenergetic diet with meal replacement by using energycontrolled food. Those in the isoenergetic diet group lost more weight in the first months, but both groups showed significant reductions in systolic blood pressure, triglycerides, glucose and insulin at the 27-month follow-up. A comparison of a "prudent diet" (50-60\% carbohydrates, 15-20\% proteins, $<30 \%$ total fat) and Mediterranean-style diet in an overweight group of patients with metabolic syndrome showed significant improvements in pro-inflammatory factors at 2-year followup (Esposito et al. 2004). No other comparable study was found with obese patients. However, similar findings have been described in several studies in patients with cardiovascular diseases (Serra-Majem et al. 2006).

Exercise interventions and combinations of exercise and dietary counselling

The lack of regular exercise activity is thought to add significantly to the burden of obesity. The recent Cochrane review of exercise and dietary interventions in obesity (Shaw et al. 2007a,b) revealed that weight loss was small in studies of exercise alone, but that the combination of exercise and dietary change seemed to show better results. The long-term effects of a 12-week weight reduction treatment followed by a maintenance programme confirmed this. Fogelholm et al. (2000) found greater weight maintenance in the exercise group, but most cardiovascular risk factors, such as systolic blood pressure and fasting glucose, worsened, although HDL cholesterol increased positively, and the number of cases with a metabolic syndrome decreased in the exercise group. In a 2-year follow-up of a combined exercise and diet programme, patients in the intervention group lost significantly more weight (mean changes $-2.4 \pm$ $0.7 \mathrm{~kg}$ ) than the controls $(-0.1 \pm 0.5)$, who received general information about dieting, physical activity and weight loss (Mensink et al. 2003). Additionally, 2-h glucose concentration following a glucose challenge test declined from 8.7 to
$8.0 \mathrm{mmol}$ in the intervention group, but increased in the control group. Wing et al. (1998) compared a combination therapy including diet, exercise and behavioural counselling with a self-help programme (LEARN) over 48 months. Weight loss was only significant in the intervention group, but fasting glucose increased in both groups.

The modest weight loss of $4.5 \mathrm{~kg}$ reduced the risk for diabetes by $30 \%$. Lindholm et al. (1995) investigated apparently healthy volunteers with at least two cardiovascular risk factors, randomising them to a group-based therapy combining dietary, physical activity and relaxation interventions with control. Total cholesterol and Framingham risk scores decreased in the intervention group after 18 months. Additionally, most of the other cardiovascular risk factors improved.

Pan et al. (1997) described cumulative incidence numbers of diabetes after different non-surgical treatments. Participants were randomly assigned to one diet, exercise, or diet plus exercise, and a control group. As an effect at 6-year follow-up, diabetes incidence was $67.7 \%$ in controls compared to $43.8 \%$ in diet, $41.1 \%$ in exercise, and $46 \%$ in the diet plus exercise group.

\section{Psychological interventions}

Effects of different psychotherapy styles in obesity and overweight have been compared and analysed by the Cochrane Collaboration (Shaw et al. 2007a,b). The majority of included studies assessed behavioural and cognitivebehavioural weight reduction strategies and favoured the combined treatment of behaviour therapy, dietary change and exercising to improve weight loss. The Cochrane review did not include any publications with cardiovascular long-term results. However we identified two studies presenting results of cardiovascular changes at the 18-month follow-up. Stevens et al. (2001) examined overweight patients enrolled in a 12-week behavioural therapy programme and reported that those with weight loss showed a decrease in blood pressure at 18-month follow-up. Additionally, the risk ratio for hypertension in the intervention group was 0.58 at 18 months and 0.81 at 36 months, and those who lost and maintained at least $4.5 \mathrm{~kg}$ weight loss at 6 months had the best improvements in blood pressure and lowered relative risk for hypertension.

In contrast, no similar effect was found in a 5-year followup of a group of healthy pre-menopausal women (mean BMI 25) after a 20-week intervention, which included cognitive behavioral therapy, either at the 30-month follow-up or at the 42- or 54-month time points (Kuller et al. 2001). However, the cognitive behavioural therapy had a significant effect on lowering low-density cholesterol, increasing triglycerides and glucose level and having a greater weight loss ( $0.90 \mathrm{~kg}$ in intervention group) at 5-year follow-up, whereas controls gained $+2.35 \mathrm{~kg}$ in weight at the same time. 


\section{Pharmacological interventions}

Few studies of the most commonly used weight reduction drugs examined effects on cardiovascular risk factors. Thereby, several pharmacological approaches are actually investigated in order to define their potential role in longterm therapy (Deedwania and Gupta 2006). Five studies compared dieting combined with orlistat and single dieting and found similar positive effects on weight reduction as well as in terms of reduced cardiovascular risk. For instance, Davidson et al. (1999) found a decrease in total cholesterol and LDL cholesterol, as well as serum glucose and insulin being related to the degree of weight change. Two longer term investigations with a follow-up of 2 years showed similar lipid changes. An intervention of a lowcalorie diet with orlistat (Rossner et al. 2000) and a therapy of orlistat with a specific guidance by a physician on a reduced energy diet and increase in exercise (Hauptman et al. 2000) resulted in similar LDL reductions. Besides the positive effects on LDL cholesterol, also fasting blood glucose decreased in an 18-month orlistat plus diet trial (Krempf et al. 2003). The 4-year long XENDOS study investigated the changes in diabetes incidence during a lifestyle weight-reduction programme plus orlistat or placebo (Torgerson et al. 2004) and found a significant reduction of the diabetes incidence in the orlistat group only. The latest article on orlistat and a very low energy diet (Richelsen et al. 2007) underlines the earlier results. Subjects treated with orlistat showed less weight regain after 3 years of treatment, but no differences in cardiovascular risk factors compared with a very low energy diet. However, the incidence rate of newly diagnosed type 2 diabetes was lower in the orlistat group.

Additionally, the Diabetes Prevention Program Research Group (2002) investigated changes of the incidence rate by using a combination of diet and metformin, an oral antidiabetic agent, in a non-diabetic patient sample with impaired glucose tolerance during an average follow-up of 2.8 years. They compared the metformin group with a placebo group and an intensive lifestyle therapy, in which participants received a 16-lesson curriculum on diet, exercise and behaviour modification. Lifestyle changes and treatment with metformin showed both effects on weight loss and changed fasting blood glucose levels, but lifestyle treatment was more effective in reducing the incidence rate of diabetes. A multicenter study with acarbose, another antidiabetic drug, achieved a significant risk reduction in developing a cardiovascular disease (e.g., stroke, myocardial infarction, or sudden death) and in hypertension incidence in the intervention sample of patients with impaired glucose tolerance (Chiasson et al. 2003). Participants had received encouragement to improve exercise and to lose weight and take either acarbose or placebo. To date, no other research group has published similar results with antidiabetic therapy modalities; however, other anti-obesity drugs are currently being investigated.

For the newer substances such as sibutramine and rimonabant, several studies exist showing their positive effects on weight and metabolism for at least 1 year (Curioni and Andre 2006). Regarding long-term change of cardiovascular risk factors only one study investigated changes of lipid levels and blood pressure during a treatment with sibutramine at 24 months. All patients participated in a 6-month diet and exercise therapy (James et al. 2000). During the 18-month weight maintenance, those randomly assigned to the intervention group received $10 \mathrm{mg}$ sibutramine and the control group a placebo. All patients showed a decrease in triglycerides, LDL cholesterol and insulin during the first 6 months, but only in the sibutramine group were changes sustained. HDL cholesterol rose positively in both groups during the 2 nd year. Despite the fact that the intervention group reduced more weight, their blood pressure increased in an unfavourable way and $3 \%$ of the patients had to be withdrawn because of their hypertonic reaction.

Another anti-obesity drug in the late-stages of clinical development is rimonabant, a selective endocannabinoid antagonist. A critical review of the Cochrane collaboration (Curioni and Andre 2006) described four existing intervention studies: RIO-Europe (Van Gaal et al. 2005), RIOLipids (Despres et al. 2005), RIO-Diabetes (Hollander 2007), and RIO North America Study (Pi-Sunyer et al. 2006). Three of them had a follow-up of 1 year. Pi-Sunyer et al. (2006) showed significantly more weight loss for $20 \mathrm{mg}$ rimonabant compared to placebo, lower levels of triglycerides and a marked increase in high-density lipoprotein levels in the 1 st year for the rimonabant-treated group. In the 2nd year, those switched from rimonabant to placebo had a weight regain, whereas those who were maintained on rimonabant had a sustained weight loss combined with positive changes in cardiometabolic risk factors.

\section{Discussion}

The aim of the systematic review was to describe the current evidence of non-surgical obesity treatment on cardiovascular risk reduction. Considering that obesity is a chronic disease of multifactorial aetiology (Orzano and Scott 2004), long-term treatment seems to be necessary for successful improvement in well-being and general health. Reviewing the literature, a great variety of approaches, such as dieting, exercising, behavioural and pharmacological treatment, was found, most of them comparing diet with exercising and exercising combined with medication. Generally, data on the evidence of non-surgical treatment 
of obesity (including very low calorie diets and cognitive behavioural therapy) revealed that the effect of such interventions is marked and has been classified as evidence A (McTigue et al. 2003; Shaw et al. 2007a, b).

The review of RCTs indicates evidence for improved blood pressure by dieting and by behavioural therapy. Thereby, lipids improved in a favourable way in diet interventions, exercising, pharmacotherapy (like orlistat, sibutramine and rimonabant), and combined therapies. Obviously, medications such as orlistat, sibutramine, and rimonabant are able to add supplemental benefits compared to the therapies where weight loss alone is the aim (such as low-calorie diets or exercising). However, it remains to be elucidated whether and to what extent regular physical exercise exerts an additional effect to weight loss on blood lipids. Similarly, effects on glucose or insulin levels were found in diet, exercise, combined treatment, behavioural therapy, and medication. Furthermore, reductions in the use of antihypertensive medication and in prevention of diabetes were detected. For these two cardiovascular risk factors, newer studies showed an augmented response of specific medication such as rimonabant and GLP-1 agonists (Aronne and Thornton-Jones 2007) compared to weight loss induced by behavioural therapy, low-calorie diet, and low vs. high carbohydrate diet.

According to these findings evidence exists that nonsurgical weight reduction programmes are associated with significant and clinically relevant changes in cardiovascular risk factors, although the effect on cardiovascular risk might depend on the degree of successful weight loss. The discussion of the amount of weight loss needed to improve the risk situation is ongoing, and to date the evidence of a meaningful impact on health of the amount of the weight loss achieved leads to recommendations that a small weight loss of 1\% (Reisin et al. 1978) to 2\% (Kannel et al. 2002), to modest weight loss of $10 \%$ loss of baseline weight (Goldstein 1992; Orzano and Scott 2004) in 1 year has effects on blood pressure, cholesterol level and glycemic control. Similarly a modest weight loss of $2.3-\mathrm{kg}$ reduction decreased a risk factor sum by factors $-43 \%$ in men and $-40 \%$ in women (Wilson et al. 1999), whereas a $4.5-\mathrm{kg}$ weight loss by diet and exercise was associated with a 30\% type 2 diabetes reduction (Wing et al. 1998). Interestingly, the Cochrane meta-analysis supports the fact that these cardiovascular risk changes under exercise treatment are independent of significant weight loss. However, generally lifestyle therapies such as diet and exercise programmes provide less than $5 \mathrm{~kg}$ weight loss after 2 to 4 years (Douketis et al. 2005), whereas pharmacologic therapy usually leads to 5 to $10 \mathrm{~kg}$ weight loss after 1 to 2 years.

Most weight loss studies have methodological limitations that restrict the applicability of findings to obese people assessed in everyday clinical practice. These limitations include inadequate study duration, a large proportions of subjects lost to follow-up, a lack of an appropriate usual care group, and a lack of reporting of outcomes in high-risk subgroups. Therefore, the possible benefit of weight loss on morbidity and mortality has to be calculated from an amelioration of the cardiovascular risk profile. Published estimations showed that a reduction of total cholesterol of $5 \%$ combined with an elevation of HDL cholesterol could result in a reduction of mortality of about $10-15 \%$ when reducing body weight by about $10 \%$. A reduction of blood pressure of about $5-10 \mathrm{mmHg}$ adds again about $10-15 \%$ reduction of mortality (Lean 1998). In the $20-30 \%$ of reduction of mortality, the amount of cardiovascular mortality does not exceed $15 \%$. However, positive effects after 1 or 2 years of follow-up are evident.

Clustering risk factors associated with obesity (Various 2001) as done in the metabolic syndrome may help to facilitate the diagnosis and treatment of the cardiovascular risk profile of these patients and to mainly reduce lowdensity lipoprotein (LDL) cholesterol in specific groups of individuals as an aim of a secondary prevention strategy. In concert with the ATP III recommendations [Adult Treatment Panel (version 3) of the US National Institutes of Health; see: Various 2001], the American Heart Association (AHA) and the American Diabetes Association (ADA) called for a joint effort to identify and treat cardiovascular and metabolic risk factors such as impaired glucose tolerance, prediabetes, arterial hypertension, dyslipidemia and obesity (Eckel et al. 2006), but no data are available that show a direct correlation of survival, risk minimization, or morbidity to the effective amount of weight loss. A slight but constant weight reduction seems to be equally effective in cardiovascular risk management as a large weight loss.

\section{Conclusion}

This weighted critical review shows that conservative treatment strategies consisting of pharmacological, behavioural, dietary, exercise and complementary therapies designed to reduce weight are able to ascertain significant benefits on cardiovascular risk factors. As the number of existing RCTs is rather small, more controlled studies in this area, especially long-term changes (expectedly over more than $5-10$ years) in clinically healthy obese subjects are needed.

In the future, it should be possible to individually adapt the most efficient, economic, long-term efficacious therapy in patients at risk for developing debilitating diseases as a result of overweight or obesity using conservative and surgical therapies concurrently. Moreover, the need for better ways to achieve sustained weight control is as important as a clear-cut scientific analysis based on RCTs 
in overweight and obesity. Nevertheless, we should remember that the obesity endemic is not only a medical, but mainly a societal problem, which on one hand should be considered in therapy in terms of suitable programmes of socialization (Scaglione et al. 2004) and on the other hand in prevention. Thereby, politicians as well as the food industry should become aware of their role in the prevention of this debilitating disorder in our population.

Acknowledgements We thank Prof. Andrew Steptoe for his invaluable help and assistance and Dr. Samantha Dockray for her proof-reading. We thank the Swiss National Foundation for the support of Dr. Nadine Messerli-Bürgy.

Conflict of interest statement None for all authors.

\section{References}

Aronne LJ, Thornton-Jones ZD (2007) New targets for obesity pharmacotherapy. Clin Pharmacol Ther 81(5):748-752

Berenson GS, Srinivasan SR (2001) Emergence of obesity and cardiovascular risk for coronary artery disease: the Bogalusa Heart Study. Prev Cardiol 4(3):116-121

Chiasson JL, Josse RG, Gomis R, Hanefeld M, Karasik A, Laakso M, for The STOP-NIDDM Trial Research Group (2003) Acarbose treatment and the risk of cardiovascular disease and hypertension in patients with impaired glucose tolerance. JAMA 290:486-494

Curioni C, Andre C (2006) Rimonabant for overweight or obesity. Cochrane Database Syst Rev 4:CD006162

Davidson MH, Hauptman J, DiGirolamo M, Foreyt JP, Halsted CH, Heber D, Heimburger DC, Lucas CP, Robbins DC, Chung J, Heymsfield SB (1999) Weight control and risk factor reduction in obese subjects treated for 2 years with orlistat: a randomized controlled trial. JAMA 281(3):235-242

Deedwania PC, Gupta R (2006) Management issues in the metabolic syndrome. J Assoc Physicians India 54:797-810

Despres JP, Golay A, Sjostrom L (2005) Effects of rimonabant on metabolic risk factors in overweight patients with dyslipidemia. N Engl J Med 353(20):2121-2134

Diabetes Prevention Program Research Group (2002) Reduction in the incidence of type 2 diabetes with lifestyle intervention or metformin. N Engl J Med 346:393-403

Ditschuneit HH, Fletchner-Mors M, Johnson TD, Adler G (1999) Metabolic and weight-loss effects of a long-term dietary intervention in obese patients. Am J Clin Nutr 69:198-204

Douketis JD, Macie C, Thabane L, Williamson DF (2005) Systematic review of long-term weight loss studies in obese adults: clinical significance and applicability to clinical practice. Int $\mathrm{J}$ Obes (Lond) 29(10):1153-1167

Ebbeling CB, Leidig MM, Feldman HA, Lovesky MM, Ludwig DS (2007) Effects of a low-glycemic load vs low-fat diet in obese young adults. JAMA 297:2092-2102

Eckel RH, Kahn R, Robertson RM, Rizza RA (2006) Preventing cardiovascular disease and diabetes: a call to action from the American Diabetes Association and the American Heart Association. Circulation 113(25):2943-2946

Esposito K, Marfella R, Ciotola M, Di Palo C, Giugliano F, Giugliano G, D'Armiento M, D'Andrea F, Giugliano D (2004) Effect of a Mediterranean-style diet on endothelial dysfunction and markers of vascular inflammation in the metabolic syndrome: a randomized trial. JAMA 292(12):1440-1446
Fogelholm M, Kukkonen-Harjula K, Nenonen A, Pasanen M (2000) Effects of walking training on weight maintenance after a verylow-energy diet in premenopausal obese women: a randomized controlled trial. Arch Intern Med 160(14):2177-2184

Goldstein DJ (1992) Beneficial health effects of modest weight loss. Int J Obes Relat Metab Disord 16(6):397-415

Hauptman J, Lucas C, Boldrin MN, Collins H, Segal KR (2000) Orlistat in the long-term treatment of obesity in primary care settings. Arch Fam Med 9(2):160-167

Heska S, Anderson JW, Atkinson RL, Greenway FL, Hill JO, Phinney SD, Kolotkin RL, Miller-Kovach K, Pi-Sunyer FX (2003) Weight loss with self-help compared with a structured commercial program. JAMA 289:1792-1798

Hollander P (2007) Endocannabinoid blockade for improving glycemic control and lipids in patients with type 2 diabetes mellitus. Am J Med 120(2 Suppl 1):S18-28; discussion S29-32

Hypertension Prevention Trial Research Group (1990) The hypertension prevention trial: three-year effects of dietary changes on blood pressure. Arch Intern Med 150(1):153-162

Itoh H (2003) What is 'metabolic domino effect'?-new concept in lifestyle-related diseases. Nippon Rinsho 61(10):1837-1843

James WP, Astrup A, Finer N, Hilsted J, Kopelman P, Rossner S, Saris WH, Van Gaal LF (2000) Effect of sibutramine on weight maintenance after weight loss: a randomised trial. STORM study group. Sibutramine trial of obesity reduction and maintenance. Lancet 356(9248):2119-2125

Kannel WB, Wilson PW, Nam BH, D’Agostino RB (2002) Risk stratification of obesity as a coronary risk factor. Am J Cardiol 90 (7):697-701

Krempf M, Louvet JP, Allanic H, Miloradovich T, Joubert JM, Attali JR (2003) Weight reduction and long-term maintenance after 18 months treatment with orlistat for obesity. Int J Obes (Lond) 27:591-597

Kuller LH, Simkin-Silverman LR, Wing RR, Meilahn EN, Yves DG (2001) Women's healthy lifestyle project: a randomized clinical trial: results at 54 months. Circulation 103:32-37

Lean ME (1998) Obesity-what are the current treatment options? Exp Clin Endocrinol Diabetes 106(Suppl 2):22-26

Lee M, Aronne LJ (2007) Weight management for type 2 diabetes mellitus: global cardiovascular risk reduction. Am J Cardiol 99 (4A):68B-79B

Lindholm LH, Ekbom T, Dash C, Eriksson M, Tibblin G, Scherstén B (1995) The impact of health care advice given in primary care on cardiovascular risk. CELL Study Group. BMJ 310 (6987): 1105-1109

McTigue KM, Harris R, Hemphill B, Lux L, Sutton S, Bunton AJ, Lohr KN (2003) Screening and interventions for obesity in adults: summary of the evidence for the US Preventive services task force. Ann Intern Med 139(11):933-949

Mensink M, Blaak EE, Corpeleijn E, Saris WH, de Bruin TW, Feskens EJ (2003) Lifestyle intervention according to general recommendations improves glucose tolerance. Obes Res 11 (12):1588-1596

Orzano AJ, Scott JG (2004) Diagnosis and treatment of obesity in adults: an applied evidence-based review. J Am Board Fam Pract 17(5):359-369

Pan XR, Li GW, Hu YH, Wang JX, Yang WY, An ZX, Hu ZX, Lin J, Xiao JZ, Cao HB, Liu PA, Jiang XG, Jiang YY, Wang JP, Zheng H, Zhang H, Bennett PH, Howard BV (1997) Effects of diet and exercise in preventing NIDDM in people with impaired glucose tolerance. The Da Qing IGT and Diabetes Study. Diabetes Care 20(4):537-544

Pardo Silva MC, De Laet C, Nusselder WJ, Mamun AA, Peeters A (2006) Adult obesity and number of years lived with and without cardiovascular disease. Obesity (Silver Spring) 14(7):1264-1273

Pi-Sunyer FX, Aronne LJ, Heshmati HM, Devin J, Rosenstock J (2006) Effect of rimonabant, a cannabinoid-1 receptor blocker, 
on weight and cardiometabolic risk factors in overweight or obese patients: RIO-North America: a randomized controlled trial. JAMA 295(7):761-775

Reisin E, Abel R, Modan M, Silverberg DS, Eliahou HE, Modan B (1978) Effect of weight loss without salt restriction on the reduction of blood pressure in overweight hypertensive patients. N Engl J Med 298(1):1-6

Richelsen B, Tonstad S, Rossner S, Toubro S, Niskanen L, Madsbad S, Mustajoki P, Rissanen A (2007) Effect of orlistat on weight regain and cardiovascular risk factors following a very-low-energy diet in abdominally obese patients. Diabetes Care 30:27-32

Rossner S, Sjostrom L, Noack R, Meinders AE, Noseda G (2000) Weight loss, weight maintenance, and improved cardiovascular risk factors after 2 years treatment with orlistat for obesity. European Orlistat Obesity Study Group. Obes Res 8 (1):49-61

Scaglione R, Argano C, Di Chiara T, Licata G (2004) Obesity and cardiovascular risk: the new public health problem of worldwide proportion. Expert Rev Cardiovasc Ther 2(2):203-212

Serra-Majem L, Roman B, Estruch R (2006) Scientific evidence of interventions using the Mediterranean diet: a systematic review. Nutr Rev 64(2 Pt 2):S27-S47

Shaw K, Gennat H, O'Rourke P, Del Mar C (2007a) Exercise for overweight or obesity. (No. CD003817. DOI 10.1002/14651858. CD003817.pub3.) Hamilton, US. The cochrane database of systematic reviews

Shaw K, O'Rourke P, Del Mar C, Kenardy J (2007b) Psychological interventions for overweight or obesity. (No. CD003818. DOI 10.1002/14651858.CD003818.pub2.). Hamilton, US: The cochrane database of systematic reviews
Stevens V, Obarzanek E, Cook NR, Lee IM, Appel LJ, Smith West D, Milas NC, Mattfeldt-Beman M, Belden L, Bragg C, Millstone M, Raczynski J, Brewer A, Singh B, Cohen J (2001) Long-term weight loss and changes in blood pressure: results of the Trials of Hypertension Prevention, phase II. Ann Intern Med 134(1):1-11

Swinburn B, Metcalf PA, Ley SJ (2001) Long-term (5-year) effects of a reduced-fat diet intervention in individuals with glucose intolerance. Diabetes Care 24(4):619-624

Torgerson JS, Hauptman J, Boldrin MN, Sjostrom L (2004) XENical in the prevention of diabetes in obese subjects (XENDOS) study: a randomized study of orlistat as an adjunct to lifestyle changes for the prevention of type 2 diabetes in obese patients. Diabetes Care 27(1):155-161

Van Gaal LF, Rissanen AM, Scheen AJ, Ziegler O, Rossner S (2005) Effects of the cannabinoid-1 receptor blocker rimonabant on weight reduction and cardiovascular risk factors in overweight patients: 1-year experience from the RIO-Europe study. Lancet 365(9468):1389-1397

Various (2001) Detection, evaluation, and treatment of high blood cholesterol in adults. Rev Panam Salud Publica 9(5):338-344

Wilson PW, Kannel WB, Silbershatz H, D’Agostino RB (1999) Clustering of metabolic factors and coronary heart disease. Arch Intern Med 159(10):1104-1109

Wing RR, Venditti E, Jakicic JM, Polley BA, Lang W (1998) Lifestyle intervention in overweight individuals with a family history of diabetes. Diabetes Care 21(3):350-359

Yan LL, Daviglus ML, Liu K, Stamler J, Wang R, Pirzada A, Garside DB, Dyer AR, Van Horn L, Liao Y, Fries JF, Greenland P (2006) Midlife body mass index and hospitalization and mortality in older age. JAMA 295(2):190-198 